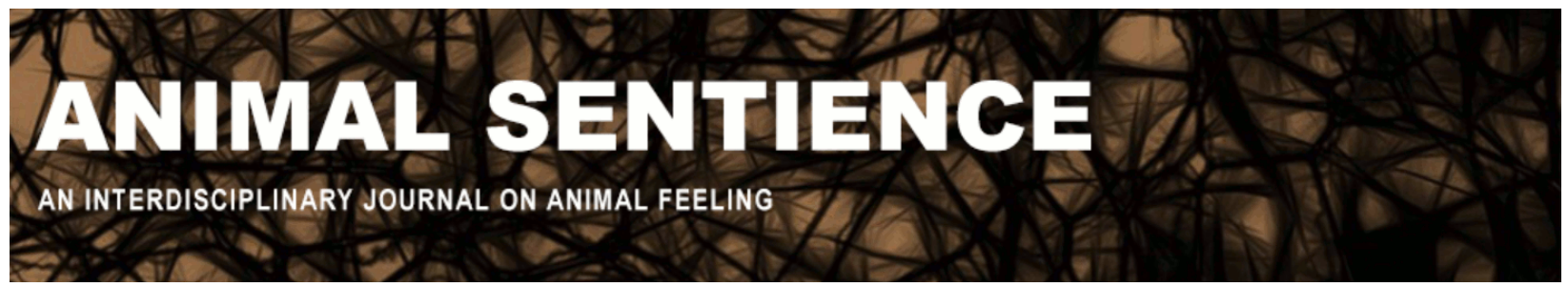

Irvine, Leslie (2016) The person and the self as social accomplishment. Animal Sentience 10(11)

DOI: $10.51291 / 2377-7478.1164$

Date of submission: 2016-09-06

Date of acceptance: 2016-09-10

(c)

This article has appeared in the journal Animal

Sentience, a peer-reviewed journal on animal

cognition and feeling. It has been made open access,

free for all, by WellBeing International and deposited

in the WBI Studies Repository. For more information,

please contact

wbisr-info@wellbeingintl.org.

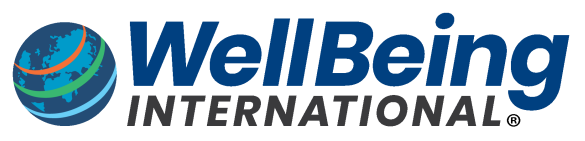

SOLUTIONS FOR PEOPLE, ANIMALS AND ENVIRONMENT 


\title{
The person and the self as social accomplishment
}

Commentary on Rowlands on Animal Personhood

\author{
Leslie Irvine \\ Professor of Sociology \\ University of Colorado at Boulder
}

\begin{abstract}
Rowlands (2016) presents a compelling argument for extending personhood to nonhuman animals. Sociological conceptions of the person also do not require that animals meet the elusive standard of self-awareness. Sociological ideas on selfhood support the claims about pre-reflective awareness and extend the requisite experiences to animals.
\end{abstract}

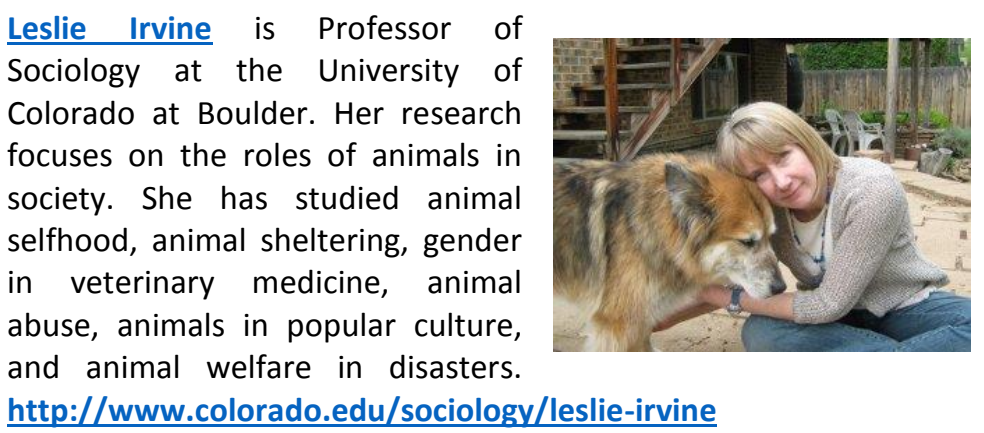

I will admit to needing little convincing, but "Are animals persons?" (Rowlands 2016) provided new ways to understand how animals qualify for the status. Rowlands begins by sketching out different ideas about personhood. He points out that it can refer to a legal sense, in which the status of person is enshrined in law, or a moral sense, in which a person is "the sort of thing to which a certain sort of moral consideration is owed." His target article does not address these ideas about personhood, but instead focuses on personhood in a metaphysical sense. This refers to essential characteristics not encompassed by legal or moral conceptions of the person. One is a person in the metaphysical sense by virtue of possessing those characteristics. As for what these characteristics are, this is where Rowlands challenges existing assumptions. He explains that debates about personhood have long relied on John Locke's definition, in which a person is "a thinking intelligent being, that has reason and reflection, and can consider itself the same thinking thing, in different times and places." In sum, personhood requires both the existence of a mental life and the ability to recognize the contents of that life as part of the "same thinking thing" that has or is the life (Rowlands 2016: 2). In other words, the thinking being must recognize, as William James (1961) put it, "I am the same as I was yesterday ... the Me of now and the Me of then are continuous" (68).

A being's ability to "consider itself" constitutes a form of self-awareness, a necessary condition for personhood. Any being that is not self-aware is not a person. Most humans qualify as persons in this sense, but debate about whether non-human animals also qualify persists. The 
inability of many species to recognize themselves in mirrors purportedly demonstrates that they lack reflective self-awareness. In other words, they cannot have the thought that "the body in the mirror is identical with me." Rowlands works his way around to resolving this, but first, he addresses the other part of Locke's conception: a unified mental life. The sight of one's image in the mirror must be somehow grouped with thoughts and states also seen as "belonging to me." Seeing an object in the mirror and recognizing the object as oneself involves first-order processes. Personhood based on reflective self-awareness also requires higher-order processes that bind that recognition with other thoughts, perceptions, acts, and states together as belonging to me. This involves meta-cognition, or the ability to think about thinking. In this view, the thoughts, acts, and other processes belong together because of another thought that they belong together. However, this higher order thought is a different kind of thought than the others. According to Rowlands, we cannot answer the question of whether the various thoughts belong together by adding another thought, for we cannot know whether this thought even belongs with the others. We cannot explain the unity of thought by saying that it depends on another level of thought. Unity of thought cannot come from a higher order thought "about" the others, for the additional order undoes the unity.

Rowlands then suggests reconsidering what it means for a thinking being to "consider itself." He proposes that the form of self-awareness involved in this process may not necessarily rely on higher-order meta-cognition. As an alternative, Rowlands makes a distinction between two different meanings of awareness. In the first case, if I say that I am aware of a book on my desk, the book's presence on the desk is independent of my awareness of it. The book is on my desk regardless of whether I am thinking about it. In the second case, if I say that I am in pain, the pain is not independent of my awareness but is part of knowing the experience. The pain doesn't exist apart from my awareness of it. My awareness in the second case is pre-reflective, built into the act of experiencing pain as pain. Knowing or experiencing something as something is not separate from the knowing or experiencing. In this sense, when a thinking being "considers itself," the act of considering includes the awareness that the act is mine. The act indicates self-awareness; the knowing or experiencing as can only occur for the subject who knows or has the experiences. There is no additional step, no other level of thought required. In this way, pre-reflective awareness provides the unified mental life necessary for personhood. Evidence of pre-reflective awareness appears among animals; Rowlands uses the example of the dog who experiences another dog as familiar. A unified mental life means that animals qualify as persons.

From a sociological perspective, two areas of research can add to the discussion. First, in addition to the legal, moral, and metaphysical senses, personhood is also a social accomplishment. Situations, interactions, and relationship provide the setting for the production of persons. The socially defined and publicly visible person can be teased apart from individuals' reflective awareness of themselves (see Cahill 1998). Across history, many human groups have been denied the status, including Jews, African Americans, slaves, the intellectually disabled, and prisoners, just to name a few. Granted, they have also been denied legal and moral personhood, but the extent to which they have been deprived of the interactional 
resources that enable the "collaborative manufacture" of the person depends on social context (Goffman 1967: 2).

Beginning in the 1990s, a body of sociological literature began to apply this perspective to animals. Studies of interactions between caregivers and the mentally disabled (Pollner and McDonald-Wikler 1985; Bogdan and Taylor 1989) provided the basis for this work. For instance, in examining how family members assign personhood to the severely disabled, Bogdan and Taylor (1989) found that caregivers attribute thinking to the disabled person, granting him or her abilities to reason and understand. Non-disabled family members also consider the disabled person a partner in interaction, with his or her gestures, body postures, and facial expressions accomplishing what spoken language would otherwise have done. Family members also see the disabled as having their own preferences, feelings, and other characteristics. Moreover, they incorporate the disabled into household routines and rituals, and thus into the narrative history of the family. In this way, social interaction also provides the material through which the disabled attain the status of person.

Clinton Sanders $(1993,1999)$ extended this to show how dog owners extend the status to their dogs. He found that owners saw their dogs as minded social actors who could act in ways that shaped their owners' definitions of situations. Owners also saw their dogs as individuals and could easily describe what a particular dog "was like" (1993: 215). They saw their dogs as having a range of emotions and demonstrating sensitivity to emotions in others. In addition, they incorporated their dogs into household practices through mealtimes, opportunities for play and exercise, and into family rituals such as birthdays and holidays. Similarly, Steven and Janet Alger (1997) observed how cats took the role of the other, defined situations, chose courses of action, and demonstrated memories of past events. These analyses offer a clear sense of the social construction of personhood among animals through everyday interaction.

Second, my own research on selfhood among companion animals meshes nicely with Rowlands's discussion of pre-reflective awareness. As I understand it, this awareness presumes a self, which is part of experiencing as. In sociology, the self has long been reserved for human beings. This is our legacy from George Herbert Mead (1962), who declared spoken language as the barrier between humans and non-humans because it enables us to understand and communicate the symbols for self, such as our names and the names of other objects. Mead recognized that animals communicate but claimed that their interaction involves an instinctual "conversation of gestures," such as when one dog growls at another who threatens to steal his bone or a cat hisses at a rival. Mead considered the "conversation of gestures" insignificant because it allegedly has only one meaning. The behavior of animals may be goal-directed, aimed at getting food, a mate, or defending territory, but it lacks the negotiated meaning that humans engage in through language. Because animals could not use language, Mead rendered them incapable of having meaningful social interaction, and therefore, lacking the selfhood that would emerge from that interaction.

Relying on language eliminates many aspects of interaction that contribute to selfhood. Moreover, it restricts those who can possess selves to human beings. The flaws in Mead's view are numerous, 
and other scholars have reviewed them in detail (see Sanders and Arluke 1993; Myers 1998; Sanders 1999). If we grant that factors beyond spoken language matter for the creation of the self, then animals can participate in the process of self-making. To do so, they must themselves be subjects. How can we sense their subjectivity? As with other people, we cannot observe it directly. We perceive it during interaction. To illustrate how this takes place, I borrow ideas about the manifestation of self that originated with William James (1961) and were later applied to infants (see Stern 1985). Because infants lack the ability to use language, their experiences can be compared to those of (at least some) animals, who have similar brain structures and musculature. Whereas human development leads to language acquisition that adds to these basic experiences, the experiences themselves are preverbal. They consist of:

(1) A sense of agency, meaning that you are the author of your actions and movements and not the author of the actions and movements of others;

(2) A sense of coherence, meaning that you understand yourself as a physical whole that is the locus of agency;

(3) A sense of affectivity, meaning that patterned qualities of feelings are associated with other experiences of the self;

(4) A sense of self-history, meaning that you maintain some degree of continuity, even while changing.

Human beings gain these experiences through interaction with others, beginning at birth. These four experiences not only underlie one's own senses of subjective experience, they also form the basis for distinguishing self from other. Combined, these four preverbal experiences constitute a "core" self (see Stern 1985: 71) around which additional senses of self accrue. I offer brief examples of how these aspects of the core self manifest themselves among animals, drawing on my research on dogs and cats and the literature on other animals (Irvine 2004a, 2004b, 2007).

\section{Agency}

Agency implies subjectivity, in that an agentic being, by definition, has desires, wishes, and intentions, along with a sense of having those things. In other words, it is the actor's awareness of having desires or wishes that is an element of selfhood, not simply having them. Agency also implies having control over one's own actions (i.e., I can sit when I decide to, and if you push me into a chair, that is a different experience) and awareness of the felt consequences of those actions. For example, my intention to sit brings the felt consequence of sitting.

Several indicators of agency appear in the first months of life, as babies begin reaching for objects and gaining hand-to-mouth skills. Infants around four months of age begin to use visual information to shape the fingers to accommodate objects of particular sizes. Because agency does not depend on language, it is feasible among other species. Some of the best examples of animals' agency come from the arena of dog training, even at the beginner's level. As Sanders (1999) explains, trainers teach dogs to exercise self-control. This implies that the dog recognizes that he or she can initiate action, since in order to control one's self one must first have a sense of will or volition. In my research at an animal shelter, I saw frequent examples of this when staff 
members sought to make under-socialized dogs more adoptable. A typical case involved a young, mixed-breed dog who jumped up on the gate of his kennel and barked wildly for attention whenever anyone came near, making most potential adopters think twice. The key to modifying the dog's behavior was to change his understanding of the cause of the rewards he receives. A dog who jumps up on his kennel and barks receives two kinds of rewards. To the extent that the behavior is self-directed (i.e., aimed at releasing energy), it is constantly rewarding. However, to the extent that the behavior is directed at others, as an attempt to gain their attention, there is only a probabilistic chance of reward. As long as the reward of attention depends upon others, it will be unpredictable. The dog does not control it. The only thing he controls (or should) is his behavior. We had to make the dog understand how to increase the probability of rewards from others. To do so, we removed him from the adoption area for a few days to reduce the foot traffic past his kennel. We scheduled regular exercise to reduce his need for the jumping. Most importantly, we stopped reinforcing his bad behavior. We paid attention to him only when he stood quietly. If he got up on his hind legs or barked, we moved away from his kennel. Because he had released some pent-up energy through exercise, the reward of attention became a higher priority. Moreover, because attention depended on others, he soon learned to control himself to get it. This subtle act of behavior modification helped the dog distinguish self from other by distinguishing different reinforcement schedules. Infants develop this ability as early as three months of age; the same probably holds for other highly social animals, with similar implications for discriminating self from other.

\section{Coherence}

If agency provides a sense of self versus other then coherence provides the boundaries of the self. Coherence gives agency somewhere to "live." Several indicators of coherence are independent of language, making them likely in non-human animals. According to the infancy research, the capacity to recognize distinct others, such as primary care-givers, becomes available at two or three months of age. Animals, too, can recognize distinct others. People who regularly work with certain animals find that animals quickly begin to recognize them. More relevant for the discussion of coherence is how animals understand that parts of people belong together. For example, during my research, I had regular contact with a dog who required several surgeries. I often restrained him while a technician drew blood and I sat with him as he woke up after his first surgery. When he recovered and became available for adoption, other people also worked with him, but whenever he saw me, he brightened up. One day, when an E-collar obscured his vision, I approached him from behind as he stood next to two other people. As I passed, I greeted them. As I did, the dog's tail wagged and he turned as if to confirm that the physical form matched the familiar voice.

Although some might dismiss this as a conditioned response (i.e., my voice had been programmed into his behavioral repertoire), another example is less easily dismissed. Animals demonstrate coherence in the act of hiding, which requires a sense of self as an object to conceal from others. Hiding "shows an awareness that the 'embodied self' is in danger and that concealment is in order" (Sanders 1999: 137; see also Allen and Bekoff 1997). Cats, having evolved as skilled predators, relied on the ability to hide in order to hunt. Janet and Steven Alger (2003) found that cats adapt their hiding into games of hide-and-seek (58). 


\section{Affectivity}

Another dimension of the core self is the capacity for emotions, which not only indicate pleasure and displeasure, but also connect the previous two self-experiences. If agency refers to experiences of self as the initiator of actions, and coherence locates those actions within an embodied entity, then affectivity refers to the ability not only to experience emotions but also to associate emotions with the other aspects of self. Affectivity assigns "ownership" to an action and its associated internal state. For instance, in face-to-face play involving mother and child, the child smiles or makes a face and the mother reacts with laughter or mock surprise. The child, experiencing pleasure at the mother's response, repeats the gesture to elicit the same emotional experience. Although the mother participates in the activities, the feeling "belongs" to the child. The research on infant development has identified signs of this capacity between three and six months of age.

It is now widely accepted that animals experience emotions. Dogs and cats experience surprise, contentment, fear, frustration, boredom, and joy, just to start the list. They form close bonds, suggesting affection and perhaps even love. Other animals also experience emotions, and research has grown steadily in recent decades. For example, orphaned elephants grieve and experience post-traumatic stress (Bradshaw et al. 2005; Poole 1998) and ravens fall in love (Heinrich 1991). Evidence suggests that animals can also associate feelings with distinct experiences and understand that they are the source of the feelings, thus suggesting the constellation of agency, coherence, and affectivity of a core self. For example, in 2012, a popular video showed a crow sledding on a jar lid. The bird slid down a rooftop on the lid, dragged it back to the top, and went down a second time before the close of the one-minute video. This exemplifies the solitary activity known as object play. Most birds and mammals engage in it (Bekoff and Byers 1998), as do some reptiles, such as turtles (Burghardt 1998), and even octopuses (Mather and Anderson 1999). Although we cannot say how the bird labeled the experience, he or she clearly enjoyed it. Judging by the effort taken to repeat it, the bird knew that he or she was the source of the experience.

\section{Self-History}

A sense of continuity, made possible by memory, completes the constellation of core selfexperiences. Memory preserves the meaning of events, objects, and others, and their associated emotions. Memory begins to operate very early in life. Among infants, motor memory enables them to learn to sit up and to suck a thumb, and perceptual and affective memory allows them to recognize familiar faces or toys and to smile upon doing so. The memory required for self-history is preverbal, and several aspects of it appear in animals. Anyone who has ever taken a dog or cat to the veterinarian knows that animals remember places. Skeptics might say that the animal "just smells fear," dismissing the reaction as instinctual. However, even if it were "only" instinct, consistently registering a particular emotion in a setting nevertheless implies a sense of continuity.

In addition to the veterinarian's office, others have documented animals' "place memory" (Lerman 1996; Sanders 1999; Alger and Alger 2003). Indeed, Kenneth Shapiro $(1990,1997)$ suggests that the lives of dogs are oriented in terms of place, rather than time, as ours are. Feline examples abound 
in the work of Steven and Janet Alger $(1997,2003)$. In their research in the cat shelter, they observed that the cats designated certain places such as cage tops and beds as "not just comfortable places for sleeping, but also safe places to relax, to find intimacy with others, and to explore their need for affection" (2003: 110). The sheltered cats learned to define these areas in the same terms, suggesting a coherent system of memory created through symbolic interaction.

A behaviorist would characterize these examples not as memory, but as simple conditioned responses. Colin Allen and Marc Bekoff (1997) make a distinction that is useful in this context. They distinguish between behavior that is "stimulus bound," meaning an invariable (or nearly so) response to external stimuli, and behavior that is "stimulus free," or motivated by internal factors (56-62). When external factors predominate over internal factors, behaviorist explanations are preferred. However, in many instances, behaviorist conclusions have been drawn from research that ignores or disregards internal factors. For example, many laboratory studies of allegedly stimulus-bound behaviors must modify conditions so that animals will be sufficiently motivated to perform according to behaviorist expectations. This is especially the case in experiments involving food rewards, in which researchers must keep animals motivated to eat even when internal responses perceive satiation. In such cases, stimulus-bound conclusions are drawn from behaviors that would under normal circumstances be stimulus free. To use an example closer to home, two of my cats regularly sleep on a fleece blanket. It is not stretching the point to say that they find this particular blanket comforting. This comfort has been to some degree conditioned. Nevertheless, if I were to produce the same blanket during an examination at the veterinarian's office, neither cat would respond with kneading and napping. The behavioral explanation becomes inadequate in contexts that involve various inputs. They require a more complex explanation, and the possibility of memory seems a reasonable alternative.

At the end of his target article, Rowlands suggests, "instead of thinking of all the ways in which animals might not be persons, or juggling with one's conception of a person to ensure that animals are disqualified, it might be more fruitful instead to think of the ways in which they are" (16). Thinking about personhood in terms of collaborative manufacture, and the self in terms of the capacities outlined here, responds to this suggestion. Extending person- and selfhood to animals does not equate persons with humans. It leaves room to acknowledge that our experiences differ from those of other animals in degree rather than kind. Humans develop selves that allow us to accomplish interactions that animals cannot undertake - and vice versa. Non-human animals develop the capacities that matter for their social lives. It would be as unfair to measure human experience by a dog's or an elephant's capacities as it would be to measure canine or elephant experience in human terms. Yet that is precisely what we have done in denying them personhood. I applaud Rowlands for leveling the playing field to include all conscious beings.

\section{References}

Alger, J. M., and S. F. Alger. 1997. Beyond Mead: Symbolic Interaction between Humans and Felines. Society \& Animals 5:65-81. . 2003. Cat Culture: The Social World of a Cat Shelter. Philadelphia: Temple University Press. 
Allen, C., and M. Bekoff. 1997. Species of Mind: The Philosophy and Biology of Cognitive Ethology. Cambridge, MA: MIT Press.

Bekoff, M., and J. A. Byers. 1998. Animal Play: Evolutionary, Comparative, and Ecological Approaches. New York: Cambridge University Press.

Bogdan, R., and S. Taylor. 1989. Relationships with Severely Disabled People: The Social Construction of Humanness. Social Problems 36:135-148.

Bradshaw, G. A., A. N. Schore, J. L. Brown, J. H. Poole, and C. J. Moss. 2005. Elephant breakdown. Nature 433: 807.

Burghardt, G. M. 1998. The Evolutionary Origins of Play Revisited: Lessons from Turtles. In Animal Play: Evolutionary, Comparative, and Ecological Approaches (pp. 1-26), edited by M. Bekoff and J. Byers. New York: Cambridge University Press.

Cahill, S. E. 1998. Toward a Sociology of the Person. Sociological Theory 16:131-148.

Goffman, E. 1967. Interaction Ritual. New York: Doubleday.

Heinrich, B. 1999. Mind of the Raven: Investigations and Adventures with Wolf-Birds. New York: Cliff Street Books.

Irvine, L. 2004a. If You Tame Me: Understanding our Connection with Animals. Philadelphia: Temple University Press. . 2004b. A Model of Animal Selfhood: Expanding Interactionist Possibilities. Symbolic Interaction 27:3-21. . 2007. The Question of Animal Selves: Implications for Sociological Knowledge and Practice. Qualitative Sociology Review 3:5-21.

James, W. 1961. The Principles of Psychology: The Briefer Course. New York: Henry Holt and Company.

Lerman, R. 1996. In the Company of Newfs. New York: Henry Holt.

Mather, J. A., and R. C. Anderson. 1999. Exploration, Play and Habituation in Octopuses (Octopus dofleini). Journal of Comparative Psychology 113:333-339.

Mead, G. H. 1962. Mind, Self and Society. Chicago: University of Chicago Press.

Myers, G. 1998. Children and Animals: Social Development and Our Connections to Other Species. Boulder, CO: Westview Press.

Pollner, M., and L. McDonald-Wikler. 1985. The Social Construction of Unreality: A Case Study of a Family's Attribution of Competence to a Severely Retarded Child. Family Process 24:241-254. Poole, J. 1998. An Exploration of a Commonality between Ourselves and Elephants. Etica \& Animali 9:85-110.

Rowlands, M. 2016. Are animals persons? Animal Sentience 2016.101.

Sanders, C. R. 1993. Understanding Dogs: Caretakers' Attributions of Mindedness in Canine-Human Relationships. Journal of Contemporary Ethnography 22:205-226. . 1999. Understanding Dogs: Living and Working with Canine Companions. Philadelphia: Temple University Press.

Sanders, C. R., and A. Arluke. 1993. If Lions Could Speak: Investigating the Animal-Human Relationship and the Perspectives of Nonhuman Others. The Sociological Quarterly 34:377-390. Shapiro, K. J. 1990. Understanding Dogs Through Kinesthetic Empathy, Social Construction, and History. Anthrozoös 3:184-195. 
1997. A Phenomenological Approach to the Study of Nonhuman Animals. In Anthropomorphism, Anecdotes, and Animals (pp. 277-295), edited by R. Mitchell, N. Thompson, and H. Miles. Albany: State University of New York Press.

Stern, D. N. 1985. The Interpersonal World of the Infant: A View from Psychoanalysis and Developmental Psychology. New York: Basic Books. 